\title{
Assessing Pinus pinea L. resilience to three consecutive droughts in central-western Italian Peninsula
}

\section{Sergio Piraino}

\begin{abstract}
Climate projections for the Mediterranean area forecast drier and hotter conditions and increasing trend in extreme climatic events such as drought. Scientific evidences reported that extreme dry spells affected the stem growth of different Mediterranean low-elevational pine forests inducing a decrease in tree resilience, defined as the capacity to resist to environmental stress and to recover pre-disturbance functioning. Despite its ecological and economic importance, thus far no study examined Pinus pinea L. (stone pine) resilience to drought events. This research reconstructed stone pine resilience by considering resistance, recovery, and the proportion of trees showing high values of both indexes of several planted stands to three consecutive spring-summer droughts occurred during the second half of the $20^{\text {th }}$ century. Local climatic conditions during dry spells modulated the species resistance and recovery. In this sense, wetter conditions promoted recovery, whereas warmer spring-summer affected stone pine resistance. Moreover, spring rather than summer droughts influenced stone pine resistance and recovery, confirming the species sensitivity to climatic conditions at the beginning of the growing season. Results indicated that while recovery did not significantly changed, the species resistance diminished along the analyzed period. Furthermore, more than $60 \%$ of the examined trees were not able to reach pre-drought growth, suggesting a moderate resilience of $P$. pinea to adverse climatic conditions. The results contribute to improve our understanding of stone pine growth dynamics in the climate-change context of increasing aridity actually occurring in the Mediterranean area, providing useful information for the sustainable management of these natural resources.
\end{abstract}

Keywords: Climate Change, Disturbance, Dry Spell, Tree Growth

the need of a deeper understanding of forest resilience to drought (IPCC 2014).

During recent years, tree-ring methods successfully contributed to reconstruct forest resilience to extreme drought in different biomes (Lloret et al. 2011, Gazol et al. 2016). For example, Juniperus spp. distributed in the Tibetan Plateau showed an overall increase in resilience to drought in the second half of the $20^{\text {th }}$ century (Fang \& Zhang 2019). Temperate forests in Central Europe exhibited age/site-dependent resilience to dry spells during recent consecutive climatic extremes (Zang et al. 2014). In moist tropical forests, resilience to drought would depend on species-specific charac-
Cátedra de Dasonomía, Facultad de Ciencias Agrarias, Universidad Nacional de Cuyo, Almirante Brown 500, Chacras de Coría - Luján de Cuyo, CPA M5528AHB Mendoza (Argentina)

@ Sergio Piraino (sergio.piraino@gmail.com)

Received: Dec 09, 2019 - Accepted: Apr 15, 2020

Citation: Piraino S (2020). Assessing Pinus pinea L. resilience to three consecutive droughts in central-western Italian Peninsula. iForest 13: 246-250. - doi: 10.3832/ifor3320-013 [online 2020-06-19]

Communicated by: Tamir Klein teristics (Rahman et al. 2019). Regarding Mediterranean woodlands, several works analyzed resilience to dry spells of low-elevational pine forests dominated respectively by $P$. halepensis and $P$. pinaster ( $\mathrm{Na}$ varro-Cerrillo et al. 2018, Serra-Maluquer et al. 2018). On the other hand, thus far no study addressed this particular topic for another important Mediterranean pine such as $P$. pinea (stone pine), possibly because of the species drought-tolerant characteristic and its inferred high resilience to dry spells (Oliveras et al. 2003). Nevertheless, it is well known that dry climatic conditions negatively impact stone pine growth (Mazza \& Manetti 2013). Furthermore, drought can trigger changes in the species physiology interacting with pollution and surfactants, affecting tree health status and survival (Tani 1991, Bussotti et al. 1995, Fady et al. 2004, Bouachir et al. 2017). Stone pine plantations play important environmental and economic roles, such as dune stabilization and nut production (Mutke et al. 2012). These forests have been long considered as ecological desert, being often undervalued by the scientific community (Bonari et al. 2017). Nevertheless, recent studies demonstrated their utility in maintaining local biodiversity, thus calling for conservation plans of this natural resource (Bonari et al. 


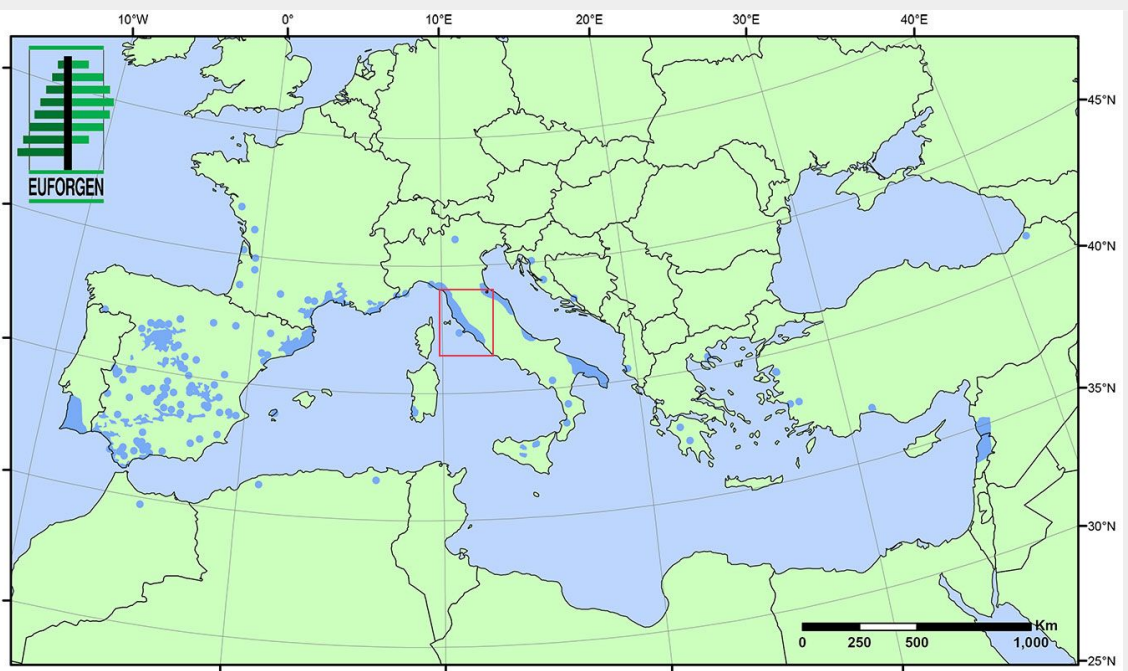

Fig. 1 - Distribution map of Italian stone pine (Pinus pinea - Fady et al. 2004). The red rectangle delimits the analyzed area.

2017). A deeper understanding of the stone pine response to extreme drought would provide useful information for sustainable management of these woodlands, a mandatory task in the climatic-change scenario of increasing aridity currently developing in the Mediterranean area (IPCC 2014). search analyzed several stone pine stands located in the coast of Central Italy aiming to: (i) reconstruct resilience to drought in term of the species resistance and recovery; and (ii) examine if consecutive dry spells cumulatively affected the species resilience.

\section{Materials and methods}

\section{Study area and dendrochronological sampling} north to mid-Tyrrhenian coasts of the Italian peninsula were analyzed (Fig. 1, Tab. 1). Woodlands are pure plantations located on sandy soils and growing under typical Mediterranean climate, with summer drought and precipitation concentrated in winter months (Raddi et al. 2009, Piraino \& RoigJuñent 2014). sampled during 2003-2004 and earlier ver-
For the abovementioned reasons, this re-

Eight stone pine stands located along the

Six of the 8 examined plantations were

sions of these tree-ring chronologies have been presented in Piraino \& Roig-Juñent (2014). Ring increment data of the remaining two stands were downloaded from the ITRDB webpage (The International TreeRing Data Bank - http://www.ncdc.noaa. gov/paleo/treering.html). The latter consisted of individual ring widths series from Marina di Bibbona (code ITAL030) and Punta Tesorino (ITAL032) sites, both shown in Raddi et al. (2009). Regarding these data, we considered only tree-ring series belonging to forest stands far from the coastline, thus minimizing the possible influence of factors other than drought (e.g., shoreline erosion) on the species resilience. Details about sampling, core preparation and ring width measurements can be found in Raddi et al. (2009) and Piraino \& Roig-Juñent (2014).

\section{Tree growth response to drought}

Drought was defined through the SPEI index (Standardized Precipitation Evapotranspiration Index - Vicente-Serrano et al. 2010). Based on previous researches (Piraino et al. 2013), a regional time series of August SPEI value with a timescale of 6months was built for the 1902-2013 period (Fig. 2). Therefore, the March-August period was considered, allowing the analysis

Tab. 1 - Geographical location, number of analyzed trees and time span of the tree-ring chronologies.

\begin{tabular}{lcccc}
\hline Site & Lat $\left({ }^{\circ} \mathrm{N}\right)$ & Long $\left({ }^{\circ} \mathrm{E}\right)$ & Trees $(\mathrm{n})$ & Time span \\
\hline San Rossore & 43.72 & 10.31 & 10 & $1890-2003$ \\
\hline Cecina & 43.31 & 10.52 & 8 & $1923-2003$ \\
\hline Marina di Bibbona & 43.30 & 10.48 & 22 & $1926-1996$ \\
\hline Punta Tesorino & 43.30 & 10.48 & 23 & $1929-1996$ \\
\hline Duna Feniglia & 42.44 & 11.22 & 12 & $1925-2003$ \\
\hline Castelporziano & 41.74 & 12.40 & 20 & $1897-2003$ \\
\hline Lago di Fogliano & 41.31 & 13.03 & 6 & $1878-2004$ \\
\hline Parco del Circeo & 41.31 & 13.03 & 15 & $1945-2004$ \\
\hline
\end{tabular}

of drought effect upon tree growth during the main drought period (summer) and the main growth season (spring). SPEI data were downloaded from the EC\&D web page (http://climexp.knmi.nl/). Drought events were established as those years when SPEI index fell in the lowest 10\% percentile. As Raddi et al. (2009) ring width series ended in 1996, the three last consecutive droughts considered in this study were 1973, 1987 and 1993 (Fig. 2).

This research considered that tree resilience is expressed by its ability to resist to and to recover from extreme climatic events (Fang \& Zhang 2019). Therefore, two different indexes were calculated: resistance $\left(R_{t}\right)$ and recovery $\left(R_{c}\right.$ - Lloret et al. 2011). In this sense, according to Lloret et al. (2011), resistance is "considered as reversal of the reduction in ecological performance during disturbance", and recovery corresponds to "the ability to recover relative to the damage experienced during disturbance". The indexes were computed as follows (eqn. 1, eqn. 2 ):

$$
\begin{aligned}
& R_{t}=\frac{B A I_{D}}{B A I_{\text {pre } D}} \\
& R_{c}=\frac{B A I_{\text {post } D}}{B A I_{D}}
\end{aligned}
$$

where $R_{t}$ is the resistance index, $R_{c}$ is the recovery index, $B A I_{D}, B A I_{\text {pred }}$ and $B A I_{\text {post }}$ are, respectively basal area index (BAI) during the drought year, mean BAI for the 3 years before and mean BAI for the 3 years following drought. BAI series were calculated from tree-ring widths through the AGE program (DPL, Dendrochronological Programme Library - Holmes 1999). Additionally to $R_{t}$ and $R_{c}$, the proportion of trees showing high resistance and recovery was calculated (Fang \& Zhang 2019). Trees were considered resistant and able to recovery after drought when $R_{t}$ and $R_{c}$ values were higher than $1\left(R_{t}>1\right.$ and $\left.R_{c}>1\right)$.

\section{Statistical analyses}

Drought effect upon stone pine growth was assessed at both the individual and stand level. At the tree scale, changes through time of $R_{t}$ and $R_{c}$ were examined by the means of ANOVA with post-hoc Tukey test (Zar 1984). Since data were not normally distributed, indexes were transformed by the Box-Cox method (Wessa 2016). At the site level, abiotic and tree biometric influence upon $R_{t}, R_{c}, R_{t}>1$ and $R_{c}>1$ was analyzed through correlation functions. Climatic variables were represented by total precipitation and mean temperature of spring-summer (March-August), spring (March-May) and summer (June-August) periods. These periods were selected in order to analyze the possible interaction among spring and summer climatic conditions upon the species resistance and recovery. Tree biometric parameters were growth (mean BAI) during drought year, and age. Regarding the latter, as precise 
age estimation of each analyzed tree was not possible, mean age was considered as the mean site chronology length when drought episodes occurred. Local precipitation and temperature data were obtained from the "Annali Idrologici" of Regione Toscana and Regione Lazio (available respectively at http://www.sir.toscana.it/ann ali-idrologici and http://www.idrografico.re gione.lazio.it/std_page.aspx-Page=annali_ idrologici.htm). Statistical analyses were run through the INFOSTAT software with its interface to R (Di Rienzo et al. 2018).

\section{Results}

A total of 116 stone pine trees distributed along 8 sites were analyzed in this research. ANOVA showed that only $R_{t}$ significantly changes along the three consecutive drought events, being values statistically lower in 1987 than in $1973(F=5.61, p=$ 0.0040 - Fig. 3). Results emerged considering proportion of trees showed a decreasing trend for the $R_{t}>1$ index (Fig. 4). Indeed, while $R_{c}>1$ values are constant, being respectively $43 \% 40 \%$ and $41 \%$ in the 1973, 1987, and 1993 dry spells, $R_{t}>1$ showed a tendency towards lower values along the three drought events, corresponding to 50\% (1973), 37\% (1987) and 35\% (1993) of the analyzed trees (Fig. 4).

Correlation functions performed at the site level indicated that the species resilience to drought is climatically-driven. In this sense, $R_{c}$, and $R_{c}>1$ are significantly and positively related to the precipitation amount of spring-summer and spring periods on one hand and of spring-summer months on the other (Tab. 2). Concerning $R_{t}$ and $R_{t}>1$, these indexes were significantly and negatively correlated to springsummer and spring temperatures respectively. No significant correlation emerged for summer period (Tab. 2). Finally, mean age and mean BAI did not represent influencing factors upon any of the examined indexes.

\section{Discussion}

This work assessed for the first time $P$. pinea resilience to drought sensu Lloret et al. (2011). Despite $21^{\text {th }}$ century extreme dry spells were not considered in this study, analyzing the possible cumulative effect of consecutive dry spells upon stone pine resistance and recovery provided novel information useful to understand the species stem growth dynamics in the current climate unstable scenario (IPCC 2014).

Stone pine resilience to drought were clearly determined by climatic conditions. The significant relations among resistance and recovery indexes on one side and temperature and precipitation on the other suggested that local cooler and wetter conditions promoted resilience. On the other hand, extreme climatic events during spring, rather than summer, affected the species resistance and recovery, in agreement with reports showing that stone pine secundary growth is mainly related to envi-

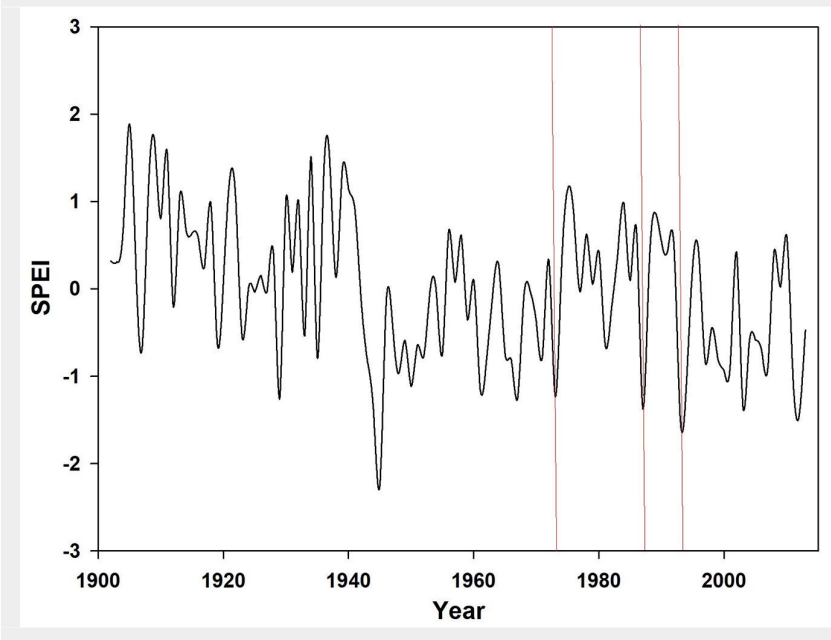

Fig. 2 - March-August SPEI of the 1902-2013 period for the examined area. Red lines represent the dry spells considered in this study.
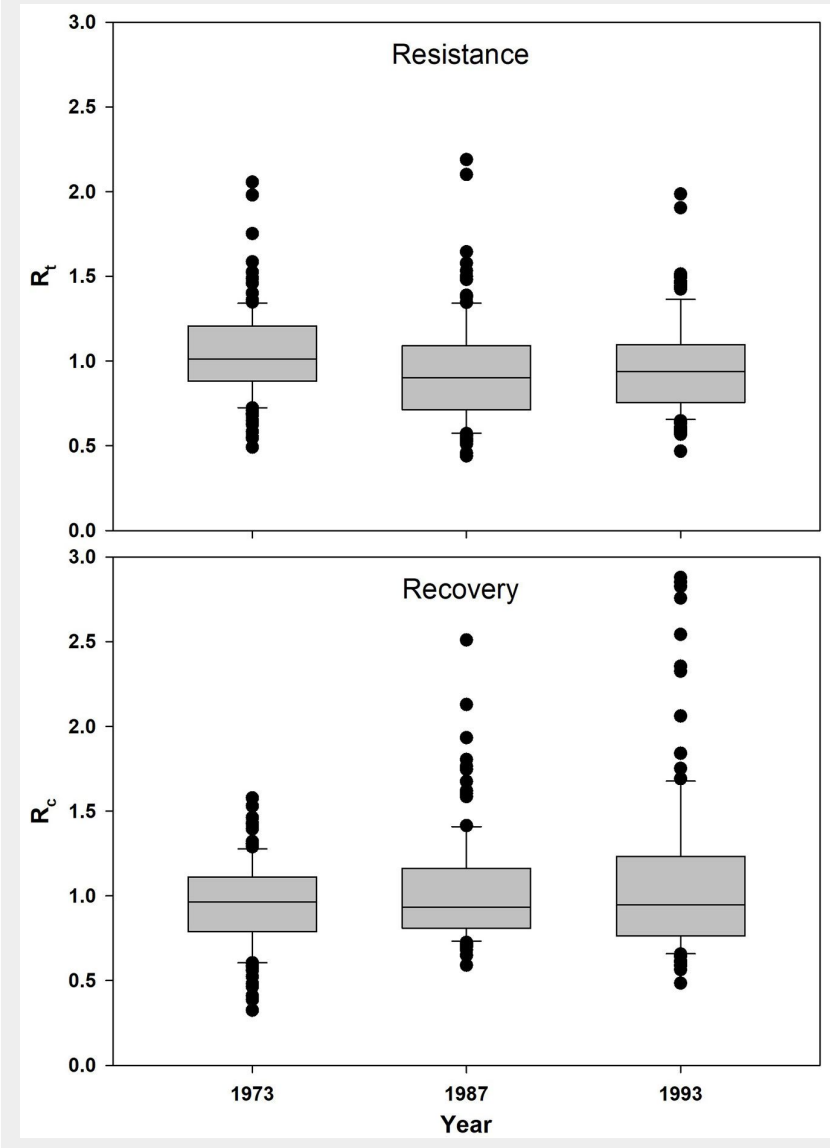

Fig. 3 - Box plots for resistance $\left(R_{t}\right)$ and recovery $\left(R_{c}\right)$ index between the different considered drought years. Each box shows the values within one interquartile distance (ID $25 \%$ above and below the median). The median is shown as a black bar. Whiskers represent values of 1.5 times the IDs and are shown as black lines. Circles represent outliers. Statistical differences are reported in the main text.

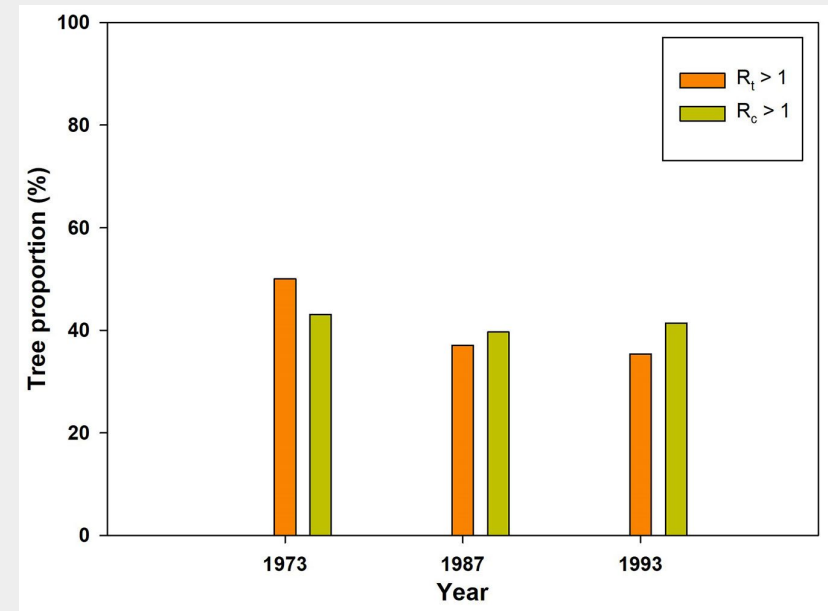

Fig. 4 - Bar plots for $R_{t}>1$, and $R_{c}>1$ between the different considered drought years. 
Tab. 2 - Results of the Pearson's correlation function computed between resistance $\left(R_{t}\right)$ and recovery $\left(R_{c}\right)$ indexes and abiotic and tree biometric variables. $(T)$ : temperature; (P): precipitation; (BAI): basal area index; ss, sp and su (subscript) refers to spring-summer, spring and summer period, respectively; $\left(^{*}\right)$ : $p<0.05$.

\begin{tabular}{llccccrrr}
\hline- & $\mathrm{P}_{\mathrm{ss}}$ & $\mathrm{T}_{\mathrm{ss}}$ & $\mathrm{P}_{\mathrm{sp}}$ & $\mathrm{P}_{\mathrm{su}}$ & $\mathrm{T}_{\mathrm{sp}}$ & $\mathrm{T}_{\mathrm{su}}$ & BAl & Age \\
\hline $\mathrm{R}_{\mathrm{t}}$ & 0.23 & $-0.42{ }^{*}$ & -0.05 & 0.37 & -0.40 & -0.40 & -0.30 & -0.24 \\
\hline $\mathrm{R}_{\mathrm{c}}$ & $0.44^{*}$ & 0.09 & $0.46 *$ & 0.14 & 0.18 & 0.01 & 0.05 & -0.00 \\
\hline $\mathrm{R}_{\mathrm{t}}>1$ & 0.11 & -0.40 & -0.14 & 0.35 & $-0.40 *$ & -0.37 & -0.35 & -0.18 \\
$\mathrm{R}_{\mathrm{c}}>1$ & $0.50^{*}$ & 0.06 & 0.40 & 0.36 & 0.15 & -0.01 & 0.12 & 0.11 \\
\hline
\end{tabular}

ronmental conditions at the beginning of the growing season (Castagneri et al. 2018).

P. pinea is an isohidric species able to tolerate drought through different physiological mechanisms, such as root mortality, stomata control and biomass allocation (Oliveras et al. 2003). Nevertheless, marked drought conditions affect the species growth diminishing needle length, reducing sap flow, and causing significantly decrease in stem increment (Teobaldelli et al. 2004, Mazza \& Manetti 2013). The positive rainfall effect upon the species recovery could be linked to increasing soil moisture and consequently higher carbohydrates production (Novak et al. 2011). Similarly, the negative relation between temperatures and resistance can reflect the detrimental effect of increasing evapotranspiration and soil water evaporation upon the species growth (Campelo et al. 2006). These physiological interpretations are sound with studies showing that under severe environmental constraints, production of wood in P. pinea may be partially or even totally absent (Novak et al. 2011). Finally, it cannot be discarded that other variables not considered in this study, such as stand density, could modulate the species resilience to drought as in other Mediterranean pines species (Serra-Maluquer et al. 2018). Unfortunately, no data were available to retrospectively examine the influence of stand characteristics upon stone pine resilience.

Apparently, no cumulative stress emerged for the species recovery, while resistance slightly decreased along the considered dry spells as showed by $R_{t}>1$ values. In this sense, $R_{t}>1$ in 2003 drought calculated from data belonging to Piraino \& Roig-Juñent (2014) represented 32\% of examined individuals ( $\mathrm{n}=71$ - data not shown), thus confirming the tendency towards lower values for this index. On the other hand, it is worth noting that approximately $60 \%$ of the analyzed stone pines were not able to reach pre-disturbance growth following drought episodes, which suggests a moderate ability of $P$. pinea to recover from particularly adverse climatic conditions. As stated in Fang \& Zhang (2019), using proportion of trees can provide additional information which can be hidden by analysis performed considering only mean values of the resilience indexes, minimizing the effect that few outperforming trees can have upon a regional response to drought. Finally, these results encourage future researches focusing on possible higher performance of some of the genotypes examined in this study when facing extreme drought events, an information that would surely contribute to improve the conservation of this natural resource.

Concluding, the results emerged in this study suggested that $P$. pinea resilience will likely be threatened by more arid conditions expected for the Mediterreanean area, with a consequent decline in the species resistance rather than recovery. This novel information should be considered in management plans, particularly in the scenario of increasing frequency of extreme drought events anticipated for the Mediterranean basin (Giorgi \& Lionello 2008, Boberg \& Christensen 2012, IPCC 2014).

\section{Acknowledgements}

Dr. Gianluca Piovesan and Dr. Alfredo Di Filippo (Dendrology Lab, University of Tuscia, Viterbo, Italy) are both greatly acknowledge for supervising the development of earlier versions of $P$. pinea tree-ring chronologies. Special thanks to Sabrina Raddi and Paolo Cherubini for sharing data through the ITRDB webpage. Thanks are due also to the Authorities of the National Parks that allowed sampling. Two anonymous reviewers are greatly acknowledged for their revisions that improved the manuscript.

\section{References}

Allen CD, Macalady AK, Chenchouni H, Bachelet $D$, McDowell $N$, Vennetier $M$, Kitzberger $T$, Rigling A, Breshears DD, Hogg EH, Gonzalez P, Fensham R, Zhang Z, Castro J, Demidova N, Lim J-H, Allard G, Running SW, Semerci A, Cobb N (2010). A global overview of drought and heatinduced tree mortality reveals emerging climate change risks for forests. Forest Ecology and Management 259: 660-684. - doi: 10.1016/ j.foreco.2009.09.001

Boberg F, Christensen JH (2012). Overestimation of Mediterranean summer temperature projections due to model deficiencies. Nature Climate Change 2 (6): 433-436. - doi: 10.1038/nclimate1 454

Bonari G, Acosta ATR, Angiolini C (2017). Mediterranean coastal pine forest stands: under- storey distinctiveness or not? Forest Ecology and Management 391: 19-28. - doi: 10.1016/j.for eco.2017.02.002

Bouachir BB, Khorchani A, Guibal F, El Aouni MH, Khaldi A (2017). Dendroecological study of $\mathrm{Pi}$ nus halepensis and Pinus pinea in northeast coastal dunes in Tunisia according to distance from the shoreline and dieback intensity. Dendrochronologia 45: 62-72. - doi: 10.1016/j.dendr 0.2017.06.008

Breda N, Badeau V (2008). Forest tree responses to extreme drought and some biotic events: towards a selection according to hazard tolerance? Comptes Rendus Geosciences 340: 651662. - doi: 10.1016/j.crte.2008.08.003

Bussotti F, Cenni E, Ferretti M, Cozzi A, Brogi L, Mecci A (1995). Forest condition in Tuscany (Central Italy). Field surveys 1987-1991. Forestry 68 (1): 11-24. - doi: 10.1093/forestry/68.1.11 Campelo F, Nabais C, Freitas H, Gutiérrez E (2006). Climatic significance of tree-ring width and intra-annual density fluctuations in Pinus pinea from dry Mediterranean area in Portugal. Annals of Forest Science 64: 229-238. - doi: 10.1051/forest:2006107

Castagneri D, Battipaglia G, Von Arx G, Pacheco A, Carrer M (2018). Tree-ring anatomy and carbon isotope ratio show both direct and legacy effects of climate on bimodal xylem formation in Pinus pinea. Tree Physiology 38 (8): 10981109. - doi: 10.1093/treephys/tpy036

Di Rienzo JA, Casanoves F, Balzarini MG, Gonzalez L, Tablada M, Robledo CW (2018). InfoStat version 2018. Centro de Transferencia InfoStat, FCA, Universidad Nacional de Córdoba, Argentina. [online] URL: http://www.infostat.co m.ar

Fady B, Fineschi S, Vendramin GG (2004). EUFORGEN Technical guidelines for genetic conservation and use of Italian stone pine (Pinus pinea). International Plant Genetic Resources Institute, FAO, Rome, Italy, pp. 6. [online] URL: http://books.google.com/books?id=Z5AhkIWzie oC

Fang O, Zhang QB (2019). Tree resilience to drought increases in the Tibetan Plateau. Global Change Biology 25 (1): 245-253. - doi: 10.1111/ gcb.14470

Gazol A, Camarero JJ, Anderegg WRL, VicenteSerrano SM (2016). Impacts of droughts on the growth resilience of Northern Hemisphere forests. Global Ecology and Biogeography 26: 166176. - doi: 10.1111/geb.12526

Giorgi F, Lionello P (2008). Climate change projections for the Mediterranean region. Global and Planetary Change 63 (2-3): 90-104. - doi: 10.1016/j.gloplacha.2007.09.005

Holmes RL (1999). Dendrochronology program library (DPL) users manual. Laboratory of TreeRing Research, University of Arizona, Tuscon, AZ, USA.

IPCC (2014). IPCC fifth assessment report climate change 2014. Synthesis report summary for policymaker. Intergovernmental Panel on Climate Change, Geneva, Switzerland, pp. 1-35.

Lloret F, Keeling EG, Sala A (2011). Components of tree resilience: effects of successive lowgrowth episodes in old ponderosa pine forests. Oikos 120 (12): 1909-1920. - doi: 10.1111/j.1600-07 06.2011.19372.x

Mazza G, Manetti MC (2013). Growth rate and cli- 
mate responses of Pinus pinea L. in Italian coastal stands over the last century. Climatic Change 121: 713-725. - doi: 10.1007/s10584-0130933-y

Mutke S, Calama R, González-Martínez SC, Montero G, Gordo FJ, Bono D, Gil L (2012). Mediterranean Stone pine: botany and horticulture. Horticultural Reviews 39: 153-201. - doi: 10.1002/ 9781118100592.ch4

Navarro-Cerrillo R, Rodriguez-Vallejo C, Silveiro E, Hortal A, Palacios-Rodríguez G, Duque-Lazo J, Camarero JJ (2018). Cumulative drought stress leads to a loss of growth resilience and explains higher mortality in planted than in naturally regenerated Pinus pinaster stands. Forests 9 (6): 358. - doi: 10.3390/f9060358

Novak K, De Luis M, Cufar K, Raventós J (2011) Frequency and variability of missing tree rings along the stems of Pinus halepensis and Pinus pinea from a semiarid site in SE Spain. Journa of Arid Environments 75 (5): 494-498. - doi 10.1016/j.jaridenv.2010.12.005

Oliveras IJ, Martínez-Vilalta J, Jimenez-Ortiz MJ, Lledó A, Escarré A, Piñol J (2003). Hydraulic properties of Pinus halepensis, Pinus pinea and Tetraclinis articulata in a dune ecosystem of Eastern Spain. Plant Ecology 169: 131-41. - doi: 10.1023/A:1026223516580
Piraino S, Camiz S, Di Filippo A, Piovesan G, Spada F (2013). A dendrochronological analysis of Pinus pinea $\mathrm{L}$. on the Italian mid-Tyrrhenian coast. Geochronometria 40 (1): 77-89. - doi: 10.2478/s13386-012-0019-z

Piraino S, Roig-Juñent FA (2014). North Atlantic Oscillation influences on radial growth of Pinus pinea on the Italian mid-Tyrrhenian coast. Plant Biosystems 148 (2): 279-287. - doi: 10.1080/1126 3504.2013.770806

Raddi S, Cherubini P, Lauteri M, Magnani F (2009). The impact of sea erosion on coastal Pinus pinea stands: a diachronic analysis combining tree-rings and ecological markers. Forest Ecology and Management 257 (3): 773-781. doi: 10.1016/j.foreco.2008.09.025

Rahman M, Islam M, Bräuning A (2019). Speciesspecific growth resilience to drought in a mixed semi-deciduous tropical moist forest in South Asia. Forest Ecology and Management 433: 487-496. - doi: 10.1016/j.foreco.2018.11.034

Serra-Maluquer X, Mencuccini M, Martínez-Vilalta J (2018). Changes in tree resistance, recovery and resilience across three successive extreme droughts in the northeast Iberian Peninsula. Oecologia 187 (1): 343-354. - doi: 10.1007/ s00442-018-4118-2

Tani A (1991). Nota sui possibili dati da siccitá in
Pinus pinea L. [Note about possible drought damages for Pinus pinea L.]. Monti e Boschi: 1012. [in Italian]

Teobaldelli M, Mencuccini M, Piussi P (2004). Water table salinity, rainfall and water use by umbrella pine trees (Pinus pinea L.). Plant Ecology 171 (1-2); 23-33. - doi: 10.1023/B:VEGE.00000 29384.40192.cc

Vicente-Serrano SM, Beguería S, López-Moreno JI (2010). A multi-scalar drought index sensitive to global warming: the Standardized Precipitation Evapotranspiration Index - SPEI. Journal of Climate 23: 1696-1718. - doi: 10.1175/2009JCLI29 09.1

Wessa P (2016). Box-cox normality plot (v1.1.12). In: "Free Statistics and Forecasting Software (v1.2.1)". Office for Research Development and Education, web site. [online] URL: http://www. wessa.net/rwasp_boxcoxnorm.wasp/

Zang C, Hartl-Meier C, Dittmar C, Rothe A, Menzel A (2014). Patterns of drought tolerance in major European temperate forest trees: climatic drivers and levels of variability. Global Change Biology 20 (12): 3767-3779. - doi: 10.1111/ gcb.12637

Zar JH (1984). Biostatistical analysis ( $2^{\text {nd }}$ edn). Prentice-Hall, Englewood Cliffs, NJ, USA, pp. 718. 